\title{
Effect of high dose versus low dose of atorvastatin therapy on inflammation and coagulation factors in type 2 diabetic patients; a randomized clinical trial study
}

\author{
Mitra Niafar ${ }^{\circledR}$, Amir Bahrami1', Neda Lotfi Yagin ${ }^{2,3}$, Farzad Najafipour ${ }^{1}$, Naser Aghamohammadzadeh', Vahideh \\ Sadra $^{1 * \mathbb{D}}$ \\ ${ }^{1}$ Endocrine Research Center, Tabriz University of Medical Sciences, Tabriz, Iran \\ ${ }^{2}$ Nutrition Research Center, Department of Biochemistry and Diet Therapy, Faculty of Nutrition, Tabriz University of Medical \\ Sciences, Tabriz, Iran \\ ${ }^{3}$ Student Research Committee, Tabriz University of Medical Sciences, Tabriz, Iran
}

\section{*Correspondence to}

Vahideh Sadra,

Email:

Sadra.vahideh@gmail.com

\section{Received 5 December 2018} Accepted 10 February 2019 Published online 23 February 2019

Keywords: Hydroxymethylglutaryl $\mathrm{CoA}(\mathrm{HMG}-\mathrm{CoA})$ reductase,

Atorvastatin calcium,

Inflammation, Diabetes mellitus,

Inflammation,

Coagulation factors

\section{Abstract}

Introduction: Statins are one of the most widely used therapies in different groups of patients not only because of cholesterol-lowering properties but also due to their non-lipid related mechanisms. However, the effects of atorvastatin on inflammatory and coagulation markers in type 2 diabetic patients are not well examined.

Objectives: To evaluate, the effects of two different doses of atorvastatin on lipid profile, inflammatory coagulation markers, and liver enzymes in type 2 diabetic patients.

Patients and Methods: In a randomized double-blinded controlled trial, 150 diabetic patients were randomly assigned to get atorvastatin $10 \mathrm{mg} / \mathrm{d}(\mathrm{n}=74)$ or $40 \mathrm{mg} / \mathrm{d}(\mathrm{n}=76)$ for 12 weeks. The concentration of biomarkers was determined both at the onset of the study as well as at the completing time of the intervention.

Results: Significant differences between the mean levels of lipid profiles, fibrinogen, interleukin-1 (IL-1) and IL- 6 were observed between two groups after three months treatment with atorvastatin 10 and $40 \mathrm{mg} / \mathrm{d}$ $(P<0.05)$. Furthermore, significant improvement in all blood values after atorvastatin $40 \mathrm{mg} / \mathrm{d}$ ingestion was observed $(P<0.05)$ except for homocysteine and creatine phosphokinase $(\mathrm{CPK})$ levels $(P>0.05)$.

Conclusion: Atorvastatin therapy especially with higher dose was associated with inflammation and coagulation parameters improvement in diabetic individuals.

Trial Registration: Registration of randomized double-blinded clinical trial has been approved in Iranian registry of clinical trial (identifier: IRCT201502226710N5; http://www.irct.ir/trial/7136).

Citation: Niafar M, Bahrami A, Lotfi Yagin N, Najafipour $F$, Aghamohammadzadeh N, Sadra V. Effect of high dose versus low dose of atorvastatin therapy on inflammation and coagulation factors in type 2 diabetic patients; a randomized clinical trial study. Immunopathol Persa. 2019;5(1):e01. DOI 10.15171/ipp.2019.01.

\section{Introduction}

Type 2 diabetes mellitus as chronic metabolic disorder, is characterized by inappropriate hyperglycemia due to the deficiency in or resistance to insulin (1). It has gotten pandemic proportions and regarded as one of the causes of healthcare costs, incapability, and mortality (2). Diabetes incidence throughout the world is in a growing trend since 1980 , going up from $4.7 \%$ to a double $8.5 \%$ in 2014 in adult individuals according to the World Health Organization (WHO) 2016 report (3). Insulin resistance can result in vasoconstriction, thrombosis, inflammation and increasing the risk of cardiovascular disease, including stroke and myocardial infarction (4). The best characterized and well standardized inflammation biomarker is $\mathrm{C}$-reactive protein (CRP), while studies

\section{Key point}

Our data revealed a significant difference in the mean levels of lipid profiles, fibrinogen, interleukin-1 (IL-1) and interleukin-6 (IL-6) between two diabetic patients groups after three months treatment with atrovastatin 10 and 40 $\mathrm{mg} / \mathrm{d}$.

have approved its role as a precursor of the type 2 diabetes and metabolic syndrome (5). Furthermore, hyperglycemia can cause endothelial dysfunction in diabetes mellitus which is considered as a significant reason in the pathogenesis of diabetic micro-and macroangiopathy in different types of diabetes (6). Different glycol-oxidative products can decrease nitric oxide production, anticoagulant properties, raise the platelet aggregation,

\footnotetext{
Copyright $(0) 2019$ The Author(s); Published by Nickan Research Institute. This is an open-access article distributed under the terms of the Creative Commons Attribution License (http://creativecommons.org/licenses/by/4.0), which permits unrestricted use, distribution, and reproduction in any medium, provided the original work is properly cited.
} 
the expression of the adhesion molecules, cytokines and chemokines, and the production of reactive oxygen species from the endothelium (6). Moreover, the blood levels of homocysteine (Hcy), a Sulphur-containing amino acid which is involved in the methionine metabolism, is also involved in diabetic vascular complications (7), while the elevated levels of this amino acid have been implicated with insulin resistance (7). However, lipidlowering drugs especially statins (inhibitors of 3-hydroxy3-methylglutaryl-CoA [HMG-CoA] reductase the main enzyme in the synthesis of cholesterol) are one of the most widely used therapies in different groups of patients not only because of cholesterol-lowering properties but also due to their "pleiotropic mechanisms" (8). The reduction in vascular inflammation and oxidative stress and improvement in atherosclerotic plaque stability, are some examples of statins pleiotropic effects (9). More recently, intensive lipid lowering with higher statin doses over regularly used doses have gained more attention because they might have significant therapeutic benefits (10). However, in a meta-analysis by Yicong et al, no significant decrease in low density lipoprotein-cholesterol (LDL-C) and CRP after treatment with low-dose versus high-dose statin plus ezetimibe was detected (11). Furthermore, the effects of different doses of atorvastatin on inflammatory and coagulation markers in type 2 diabetic patients are not well studied.

\section{Objectives}

The aim of this study was to examine the effects of high dose versus low dose of atorvastatin on inflammatory and coagulation markers in type 2 diabetes mellitus at the same time.

Patients and Methods

Study design

This study was designed and carried out according to the instructions presented in the Declaration of Helsinki. Written informed consent was obtained from all participants. This randomized clinical trial study was conducted on 200 type 2 diabetic patients who were referred to endocrinology and diabetes unit of Imam Reza hospital (Tabriz, Iran). Sample size was computed according to the primary information attained from the Yicong et al, trial for high-sensitivity C-reactive protein (hs-CRP). Considering $\alpha=0.05$ and a power of $80 \%$, the sample size was calculated as 93 per group. This number was raised up to 100 per group to compensate for dropouts. Previous history of diabetes or the American Diabetes Association (ADA) criteria were regarded as the diabetes diagnosis criterion. Study participants were aged $>18$ years old with a fasting triglyceride (TG) $<500 \mathrm{mg} /$ $\mathrm{dl}$ and LDL-C $>70 \mathrm{mg} / \mathrm{dL}$. Pregnancy or lactation, history of any metabolic disorder such as kidney and liver disease and also type 1 diabetes were considered as exclusion criteria (Figure 1).

\section{Drug Intervention}

When eligible, participants were randomly allocated to take either a low $10 \mathrm{mg}$ daily dose of atorvastatin (group A) or high $40 \mathrm{mg}$ daily dose (group B). Subjects were asked

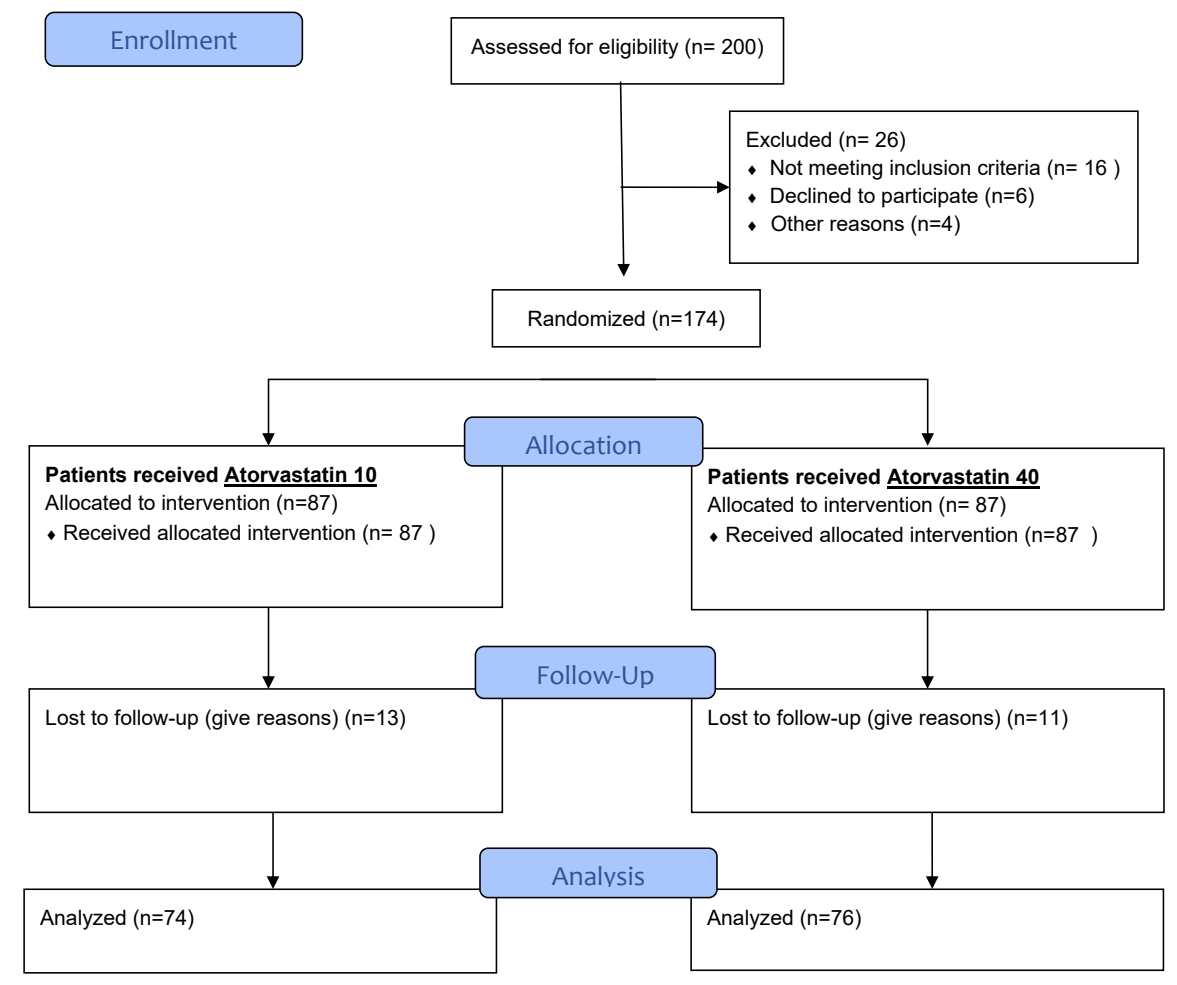

Figure 1. CONSORT flow diagram for the study. 
to take 1 tablet per day for 12 weeks.

Clinical assessments and sample collection and analysis

Assessment of clinical parameters including body mass index (BMI), blood pressure (BP), and clinical data such as lipid profile, fasting blood sugar (FBS), HbA1C, interleukin-1 (IL-1), IL-6, CRP, alanine aminotransferase (ALT), aspartate aminotransferase (AST), fibrinogen, creatine phosphokinase $(\mathrm{CPK})$ and homocysteine were evaluated at baseline and at the end of the study. BMI was calculated by dividing the body weight in kilograms into the square of the height in meters $\left(\mathrm{kg} / \mathrm{m}^{2}\right)$. After 12-hour overnight fasting, the blood samples were collected and after the serum separation, samples were frozen at $-70^{\circ} \mathrm{C}$ until analysis. Serum total cholesterol, HDL-C, LDL-C, and TG concentrations were determined by enzymatic procedures. Glucose levels were examined by an automated enzymatic/colorimetric assay. Serum IL-1, IL-6, HbA1C and CRP were analyzed with sandwich-type immunoassay methods, while, serum ALT and AST serum levels were also quantified using commercially available kits by automatic biochemistry analyzer. Total plasma fibrinogen was determined by a Fibri-Prest Automate method and homocysteine levels determined by homocysteine Elisa kits.

\section{Ethical issues}

This research was performed following the Declaration of Helsinki principles. Informed written consent was obtained from each patient. All information about individuals was coded and kept confidential. This study was approved by the Committee of Ethics in Human Research at Tabriz University of Medical Sciences with code Ir.rums.rec.1393168 dated 22/5/2015 and registered in Iranian Registry of Clinical Trials (IRCT) (identifier: IRCT201502226710N5; http://www.irct.ir/trial/7136).

\section{Statistical analysis}

SPSS software, version 21.0 was used to analyze the data using (IBM Corp., Armonk, NY, USA). Normality of the data distribution was checked by the Kolmogorov-Smirnov test. Parametric data were reported as the mean \pm standard deviation and nonparametric data were expressed as the median and interquartile range. Additionally, frequency and percentage were used to describe categorical ones. Paired $t$ test was used to analyze between-group effects of atorvastatin from baseline. Independent samples $t$ test and Mann Whitney $\mathrm{U}$ test were also used to compare differences between the two groups for parametric and nonparametric data, respectively. Accordingly, $P<0.05$ was considered as statistically significant.

\section{Results}

Table 1 demonstrates the participants' baseline data. Around 150 individuals with a mean age of $53.77 \pm 10.56$
Table 1. General characteristics of individuals

\begin{tabular}{lccc}
\hline & Group A & Group B & $\boldsymbol{P}$ \\
\hline Age, years & $52.78 \pm 11.41$ & $54.73 \pm 9.65$ & 0.25 \\
Gender,\% female & 62.16 & 65.78 & $>0.05$ \\
BMI, kg/m ${ }^{2}$ & $29.72 \pm 2.38$ & $31.63 \pm 14.53$ & 0.193 \\
\hline
\end{tabular}

Variables are expressed as mean \pm SD (standard deviation) or percent. * Statistically significant $(P<0.05)$.

years (range 26-78 years) completed the study. Around, 64\% of the participants were women. There were no significant differences between the two groups of patients' baseline characteristics as shown in Table $1(P>0.05)$. The mean levels of HbA1C (higher in group A), total cholesterol, LDL-C, and CPK (higher in group B) were significantly different between two groups before the intervention $(P<0.05$; Table 2$)$. The effects of two doses of atorvastatin on laboratory indices after 12 weeks of intervention are also presented in Table 2. Based on independent samples $t$ test (Table 3), significant differences between the mean levels of total cholesterol, LDL-C, HDL-C, fibrinogen, IL-1 and IL- 6 were observed between the groups $(P<0.05)$ while the reduction in the levels of mentioned parameters in group B was greater than group A. Furthermore, improvement in the serum FBS, HbA1C, AST, TG, total cholesterol, LDL-C, IL-1 and IL-6 values was achieved after treatment with atorvastatin 10 in group A according to paired $t$ test results while, the difference was statistically significant in those markers before and after treatment $(P<0.05)$. Accordingly in group $\mathrm{B}$, as paired $t$ test revealed, significant differences in all blood values were evident after atorvastatin administration $(P<0.05)$ with the exception for serum homocysteine and CPK levels $(P>0.05)$.

\section{Discussion}

It seems that cardiovascular events and mortality in diabetic patients could be prevented partially by statins which are largely due to their lipid-lowering property (12). In our study, after intervention with atorvastatin, the total cholesterol and LDL-C levels were decreased specially in group B. It has been well recognized that statins decrease plasma LDL-C and cholesterol levels by inhibition of HMG-CoA reductase (9). Additionally, both doses of atorvastatin lowered TGs levels. It has been well recognized that statins, particularly atorvastatin can considerably decrease TG approximately ranging from $10 \%$ to $20 \%$ (13). Regulating very low-density lipoprotein (VLDL) secretion from the liver and improvement TGrich lipoprotein clearance through induced LDL receptors from plasma appears to be the atorvastatin mechanism of action (8). Considering hsCRP levels, we found that atorvastatin $40 \mathrm{mg} / \mathrm{d}$ reduced CRP concentration by $40 \%$ which is approximately in line with previous studies. Comparable results were gained by the study of Vernagione et al (atorvastatin $10 \mathrm{mg} / \mathrm{d}$ orally for 6 months) (14). Furthermore, in a recent large population-based research, 
Table 2. Serum biomarkers following atorvastatin 10 and 40 administration before and after interventions in each group

\begin{tabular}{|c|c|c|c|c|c|c|}
\hline \multirow[t]{2}{*}{ Parameter } & \multicolumn{3}{|c|}{$\begin{array}{c}\text { Group A } \\
\text { (Atorvastatin 10, mg/d) }\end{array}$} & \multicolumn{3}{|c|}{$\begin{array}{c}\text { Group B } \\
\text { (Atorvastatin 40, mg/d) }\end{array}$} \\
\hline & Before & After & $P$ & Before & After & $P$ \\
\hline $\mathrm{FBS}(\mathrm{mg} / \mathrm{dL})$ & $184.11 \pm 52.78$ & $157.63 \pm 46.02$ & $<0.05^{*}$ & $165.47 \pm 54.89$ & $140.42 \pm 35.21$ & $<0.05^{*}$ \\
\hline $\mathrm{HbA1C}(\%)$ & $8.77 \pm 1.15$ & $8.01 \pm 0.95$ & $<0.05^{*}$ & $8.29 \pm 1.33$ & $7.71 \pm 0.77$ & $<0.05^{*}$ \\
\hline AST (IU/L) & $20.94 \pm 9.65$ & $19.67 \pm 6.94$ & $<0.05^{*}$ & $21.92 \pm 9.35$ & $20.28 \pm 5.83$ & $<0.05^{*}$ \\
\hline ALT (IU/L) & $25.81 \pm 13.42$ & $24.72 \pm 9.06$ & 0.1 & $29.77 \pm 17.09$ & $27.02 \pm 11.45$ & $<0.05^{*}$ \\
\hline $\mathrm{TG}(\mathrm{mg} / \mathrm{dL})$ & $200.6 \pm 86.76$ & $177.6 \pm 75.53$ & $<0.05^{*}$ & $185.53 \pm 70.61$ & $164.09 \pm 78.28$ & $<0.05^{*}$ \\
\hline Total cholesterol (mg/dL) & $193.54 \pm 36.94$ & $158.75 \pm 26.38$ & $<0.05^{*}$ & $212.35 \pm 41.1$ & $145.47 \pm 32.81$ & $<0.05^{*}$ \\
\hline $\mathrm{HDL}-\mathrm{C}(\mathrm{mg} / \mathrm{dL})$ & $42.68 \pm 6.85$ & $43.01 \pm 6.2$ & 0.3 & $45.32 \pm 10.06$ & $47.80 \pm 9.09$ & $<0.05^{*}$ \\
\hline LDL-C (mg/dL) & $112.06 \pm 35.28$ & $80.72 \pm 23.93$ & $<0.05^{*}$ & $129.91 \pm 37.48$ & $64.85 \pm 32.8$ & $<0.05^{*}$ \\
\hline hsCRP (mg/dL) & $3.26 \pm 2.58$ & $4.01 \pm 9.62$ & 0.49 & $2.94 \pm 2.32$ & $1.74 \pm 1.55$ & $<0.05^{*}$ \\
\hline Fibrinogen (mg/dL) & $370.64 \pm 42.66$ & $371.86 \pm 46.14$ & 0.79 & $374.26 \pm 40.15$ & $354.17 \pm 39.47$ & $<0.05^{*}$ \\
\hline Homocysteine $(\mu \mathrm{mol} / \mathrm{L})$ & $14.24 \pm 6.06$ & $14.47 \pm 6.03$ & 0.59 & $16.3 \pm 15.06$ & $13.14 \pm 5.88$ & 0.064 \\
\hline CPK (IU) & $74.97 \pm 40.24$ & $74.04 \pm 46.7$ & 0.83 & $91.32 \pm 34.63$ & $88.69 \pm 29.8$ & 0.36 \\
\hline IL-1 (pg/mL) & $97.99 \pm 23.47$ & $94.29 \pm 20.82$ & $<0.05$ & $102.81 \pm 27.94$ & $77.97 \pm 21.04$ & $<0.05^{*}$ \\
\hline IL-6 (pg/mL) & $76.48 \pm 31.01$ & $72.36 \pm 27.35$ & $<0.05$ & $81.43 \pm 39.45$ & $60.83 \pm 28.03$ & $<0.05^{*}$ \\
\hline
\end{tabular}

Data are expressed as mean \pm SD (standard deviation). ${ }^{*}$ Statistically significant $(P<0.05)$. FBS: fasting blood sugar; AST: aspartate aminotransferase; ALT: alanine aminotransferase; TG: triglyceride; HDL: high density lipoprotein; LDL: low density lipoprotein; hsCRP: high sensitivity C-reactive protein; CPK: creatine phosphokinase; IL-1:interleukine 1; IL-6: interleukin 6.

Table 3. Serum biomarkers following atorvastatin 10 and 40 administration before and after interventions between groups

\begin{tabular}{|c|c|c|c|c|}
\hline Parameter & & $\begin{array}{c}\text { Group A } \\
\text { (Atorvastatin } 10 \mathrm{mg} / \text { day) }\end{array}$ & $\begin{array}{c}\text { Group B } \\
\text { (Atorvastatin } 40 \text { mg/day) }\end{array}$ & $P$ Value \\
\hline \multirow{2}{*}{$\mathrm{FBS}(\mathrm{mg} / \mathrm{dL})$} & Before & $184.11 \pm 52.78$ & $165.47 \pm 54.89$ & 0.12 \\
\hline & After & $157.63 \pm 46.02$ & $140.42 \pm 35.21$ & 0.12 \\
\hline \multirow{2}{*}{$\mathrm{HbA1C}(\%)$} & Before & $8.77 \pm 1.15$ & $8.29 \pm 1.33$ & $<0.05^{*}$ \\
\hline & After & $8.01 \pm 0.95$ & $7.71 \pm 0.77$ & 0.53 \\
\hline \multirow{2}{*}{ AST (IU/L) } & Before & $20.94 \pm 9.65$ & $21.92 \pm 9.35$ & 0.53 \\
\hline & After & $19.67 \pm 6.94$ & $20.28 \pm 5.83$ & 0.91 \\
\hline \multirow{2}{*}{$\operatorname{ALT}(I U / L)$} & Before & $25.81 \pm 13.42$ & $29.77 \pm 17.09$ & 0.11 \\
\hline & After & $24.72 \pm 9.06$ & $27.02 \pm 11.45$ & 0.84 \\
\hline \multirow{2}{*}{$\mathrm{TG}(\mathrm{mg} / \mathrm{dL})$} & Before & $200.6 \pm 86.76$ & $185.53 \pm 70.61$ & 0.23 \\
\hline & After & $177.6 \pm 75.53$ & $164.09 \pm 78.28$ & 0.69 \\
\hline \multirow{2}{*}{ Total cholesterol (mg/dL) } & Before & $193.54 \pm 36.94$ & $212.35 \pm 41.1$ & $<0.05^{*}$ \\
\hline & After & $158.75 \pm 26.38$ & $145.47 \pm 32.81$ & $<0.05^{*}$ \\
\hline \multirow{2}{*}{ HDL-c (mg/dL) } & Before & $42.68 \pm 6.85$ & $45.32 \pm 10.06$ & 0.06 \\
\hline & After & $43.01 \pm 6.2$ & $47.80 \pm 9.09$ & $<0.05^{*}$ \\
\hline \multirow{2}{*}{ LDL-c (mg/dL) } & Before & $112.06 \pm 35.28$ & $129.91 \pm 37.48$ & $<0.05^{*}$ \\
\hline & After & $80.72 \pm 23.93$ & $64.85 \pm 32.8$ & $<0.05^{*}$ \\
\hline \multirow{2}{*}{ hsCRP (mg/dL) } & Before & $3.26 \pm 2.58$ & $2.94 \pm 2.32$ & 0.42 \\
\hline & After & $4.01 \pm 9.62$ & $1.74 \pm 1.55$ & 0.06 \\
\hline \multirow{2}{*}{ Fibrinogen (mg/dL) } & Before & $370.64 \pm 42.66$ & $374.26 \pm 40.15$ & 0.59 \\
\hline & After & $371.86 \pm 46.14$ & $354.17 \pm 39.47$ & $<0.05^{*}$ \\
\hline \multirow{2}{*}{ Homocysteine $(\mu \mathrm{mol} / \mathrm{L})$} & Before & $14.24 \pm 6.06$ & $16.3 \pm 15.06$ & 0.27 \\
\hline & After & $14.47 \pm 6.03$ & $13.14 \pm 5.88$ & 0.05 \\
\hline \multirow{2}{*}{ CPK (IU) } & Before & $74.97 \pm 40.24$ & $91.32 \pm 34.63$ & $<0.05^{*}$ \\
\hline & After & $74.04 \pm 46.7$ & $88.69 \pm 29.8$ & 0.46 \\
\hline \multirow{2}{*}{ IL-1 (pg/mL) } & Before & $97.99 \pm 23.47$ & $102.81 \pm 27.94$ & 0.25 \\
\hline & After & $94.29 \pm 20.82$ & $77.97 \pm 21.04$ & $<0.05^{*}$ \\
\hline \multirow{2}{*}{ IL-6 (pg/mL) } & Before & $76.48 \pm 31.01$ & $81.43 \pm 39.45$ & 0.39 \\
\hline & After & $72.36 \pm 27.35$ & $60.83 \pm 28.03$ & $<0.05^{*}$ \\
\hline
\end{tabular}

Data are expressed as mean \pm SD (standard deviation). ${ }^{*}$ Statistically significant $(P<0.05)$. FBS: fasting blood sugar; AST: aspartate aminotransferase; ALT: alanine aminotransferase; TG: triglyceride; HDL: high density lipoprotein; LDL: low density lipoprotein; hsCRP: high sensitivity C-reactive protein; CPK: creatine phosphokinase; IL-1:interleukine 1; IL-6: interleukin 6. 
it was revealed that statins consumers had significant lower CRP concentrations than non-statin users (15). In addition, atorvastatin considerably diminished hs-CRP levels in subjects with or without diabetes or metabolic syndrome (16). The underlying mechanism might be the prevention of CRP production by statins through reduction of IL-1b-inducible CRP expression in hepatocytes (16). In a study by Arnaud et al, statins lowered IL-6-induced CRP production at both the protein and mRNAs level in hepatocytes (17). On the other hand, it has been shown that systemic concentrations of several acutephase proteins, cytokines, and chemokines such as IL-6 are raised in diabetic patients in comparison to healthy individuals (18). IL-6 probably interfere with insulin signaling in fat, liver, and muscle cells (19), while IL-1 $\beta$ as a pro-inflammatory cytokine, prevents $\beta$-cell function and stimulates $\beta$-cell apoptosis (20). Consequently, diabetes development may stem from low-grade inflammation both due to induced insulin resistance and reduced insulin secretion. Additionally, statins have been shown to have anti-inflammatory effects (21). According to our results IL-1 and IL-6 levels improved after 12 weeks of atorvastatin therapy. Likewise, Tousoulis et al reported that levels of pro-inflammatory cytokines such as IL-6 decreased after administration of low dose atorvastatin in patients with heart failure (22). Similarly, Nawawi et al reported a significant reduction in IL-6 $(P<0.0001)$ and hs-CRP $(P<0.01)$ levels after three months intervention with atorvastatin $10 \mathrm{mg} / \mathrm{d}$ in patients with non-familial hypercholesterolemia (23). In another study, atorvastatin treatment (20-40 $\mathrm{mg} / \mathrm{d})$ attenuated pro-inflammatory markers of IL- 1 and IL- 6 in hypercholesterolemic patients (24). Anti-inflammatory effects of atorvastatin can be due to the lipid and lipid-derived substances reduction, such as lysolecithin, platelet activating factor and oxysterols which are considered as pro-inflammatory substances. Atorvastatin also diminishes the inflammatory response in tissues and inflammation factor in the arterial wall, respectively (25). Additionally, inhibition of primary redox sensitive transcription factors, mainly, NF-kB, which in turn leads to suppression of cytokines, chemokines, as well as adhesion molecules synthesis, blocks proinflammatory activation in the vascular wall are other properties of atorvastatin (26). On the other hand, higher serum Hcy concentrations in diabetic patients were also associated with insulin resistance (7). In the present study, atorvastatin administration did not cause any significant changes in Hcy concentrations neither in group A nor in group B. Although, statins have reduced plasma tHcylevels in some studies $(27,28)$, others have not reached the same conclusions (29-32). Parallel with our study, Miltiadous et al, reported that $40 \mathrm{mg} / \mathrm{d}$ atorvastatin for 10 weeks did not influence tHcy levels in 61 hyperlipidemia patients (30). Also, in another study carried out by Navarro et al, serum Hcy levels did not alter significantly in diabetic patients on hemodialysis, despite improvement in lipid profile and hsCRP levels by atorvastatin administration (31). However, Van der Loo et al, revealed that administration of $80 \mathrm{mg} / \mathrm{d}$ of atorvastatin led to an increase in Hcy plasma levels in patients with peripheral arterial disease (33). The contradictories in different studies can be partly due to the dose of statins, the intervention duration, different types of diseases and patients' metabolic profiles.

Fibrinogen is an acute-phase reactant that has a key role in thrombogenesis, inflammation, immune responses, and atherogenesis (34). The level of fibrinogen was significantly lower after 12 weeks of atorvastatin treatment than before treatment only in group B. In a study by Min et al, receiving daily atorvastatin $20 \mathrm{mg} / \mathrm{d}$ for about four weeks reduced fibrinogen levels in patients with acute ischemic stroke (34). Krysiak et al also reported a decrease in fibrinogen levels after 90 days $40 \mathrm{mg} / \mathrm{d}$ atorvastatin therapy (35). As well, in another study reduction in fibrinogen level by statins was attributed to increased transcription of the endothelial nitric oxide synthase gene and increased production of endothelial nitric oxide synthase (36). Although statins are largely well accepted, they might have adverse effects on blood glucose levels, liver enzymes and also CPK (37). However, both FBS and HbA1C levels improved in both groups after 12 weeks treatment with atorvastatin which might be explained in part by the different medications which our patients received during the study. It is also possible that atorvastatin inhibits the 3T3-L1 pre-adipocytes differentiation and suppresses glucose transporter type 4 expression which in turn leads to impaired glucose uptake in adipocytes (38). It has been shown that continuous exposure of $\beta$-cells to high cholesterol concentrations can cause their dysfunction and death (39). As it was mentioned before, atorvastatin might cause hepatotoxicity, however, atorvastatin both doses lowered AST levels. However, ALT levels reduced only by atorvastatin $40 \mathrm{mg}$. In accordance with our study, Karpisek et al also presented that atorvastatin decreased AST values after three months; however, no changes in serum ALT levels was detected (37). In addition, Farsang et al revealed that the incidence of AST/ALT $<3$ times of the higher limit of the average range in all patients was merely $0.8 \%$ without any rhabdomyolysis (38). Nevertheless, the atorvastatin hepatotoxicity and hepatic complications with 20 or $40 \mathrm{mg} / \mathrm{d}$ for 12 weeks are very unusual and hence it can be overlooked (38). Based on most clinical trials, creatine kinase $(\mathrm{CK})$ concentration more than 10 times the upper limit of normal is regarded as myopathy induced by statins (39). Ballard et al showed that CK levels increased following atorvastatin $80 \mathrm{mg} / \mathrm{d}$ consumption from $132.3 \pm 120.9 \mathrm{U} / \mathrm{L}$ at baseline to $159.7 \pm$ 170.4 U/L and 153.1 $\pm 139.4 \mathrm{U} / \mathrm{L}$ at three and six months, respectively but changes in $\mathrm{CK}$ were not associated with changes in muscle function or the incidence of myalgia (40). However, at the present study a non-significant decrease in CPK levels was observed probably due to the low dose of atorvastatin or short duration of intervention. 


\section{Conclusion}

Our finding shows that besides lipid lowering properties, atorvastatin can exert anti-inflammatory and anticoagulatory effects in type 2 diabetic patients, although effects of atorvastatin $10 \mathrm{mg} / \mathrm{d}$ seem to be milder. However, further randomized trial studies with larger population are required to clarify the exact effect of statins on inflammation, monitoring the adverse effects in higher doses or extended intervention durations.

\section{Limitations of the study}

The low number of patients may be a limitation for this study. Thus, designing a big study with more participants can be suggested.

\section{Acknowledgements}

Authors would like to acknowledge Department of Internal Medicine at Tabriz University of Medical Sciences (Iran) for their great help.

\section{Conflicts of interest}

We did not receive any support from atorvastatin manufactural company and we have no conflict of interest to declare.

\section{Ethical considerations}

Ethical issues (including plagiarism, double publication) have been completely observed by the authors. This article does not contain any studies with animals performed by any of the authors.

\section{Funding}

This work has been done as part of the sub-specialty thesis for Vahideh Sadra. This study was supported by Endocrine Research Center at Tabriz University of Medical Sciences, Tabriz, Iran (Grant No.: 93.5-7.18).

\section{References}

1. Hameed I, Masoodi SR, Mir SA, Nabi M, Ghazanfar K, Ganai BA. Type 2 diabetes mellitus: From a metabolic disorder to an inflammatory condition. World J Diabetes. 2015;6:598-612. doi: 10.4239/wjd.v6.i4.598.

2. Guerin-Dubourg A, Cournot M, Planesse C, Debussche $X$, Meilhac $\mathrm{O}$, Rondeau $\mathrm{P}$, et al. Association between Fluorescent Advanced Glycation End-Products and Vascular Complications in Type 2 Diabetic Patients. Biomed Res Int. 2017;2017:7989180. doi:10.1155/2017/7989180.

3. Poolsup N, Suksomboon N, Paw NJ. Effect of dragon fruit on glycemic control in prediabetes and type 2 diabetes: A systematic review and meta-analysis. PLoS One. 2017;12:e0184577. doi:10.1371/journal.pone.0184577.

4. Ginsberg HN. Insulin resistance and cardiovascular disease. J Clin Invest. 2000;106:453-8. doi:10.1172/JCI10762.

5. Devaraj S, Singh U, Jialal I. Human C-reactive protein and the metabolic syndrome. Curr Opin Lipidol. 2009;20:182-9. doi: 10.1097/MOL.0b013e32832ac03e.

6. Hadi HA, Suwaidi JA. Endothelial dysfunction in diabetes mellitus. Vasc Health Risk Manag. 2007;3:853-76.

7. Hoogeveen EK, Kostense PJ, Beks PJ, Mackaay AJ, Jakobs C, Bouter LM, et al. Hyperhomocysteinemia is associated with an increased risk of cardiovascular disease, especially in non-insulin-dependent diabetes mellitus: a population-based study. Arterioscler Thromb Vasc Biol. 1998;18:133-8.

8. Hsueh WA, Law RE. Cardiovascular risk continuum: implications of insulin resistance and diabetes. Am J Med. 1998;105:4S-14S. doi:10.1016/S0002-9343(98)00205-8.

9. Tsikas D, Pham VV, Suchy MT, van de Ree MA, Huisman MV, Frölich JC, et al. No effects of atorvastatin $(10 \mathrm{mg} / \mathrm{d}$ or
$80 \mathrm{mg} / \mathrm{d}$ ) on nitric oxide, prostacyclin, thromboxane and oxidative stress in type 2 diabetes mellitus patients of the DALI study. Pharmacol Res. 2015;94:1-8. doi: 10.1016/j. phrs.2015.01.004

10. Cannon $\mathrm{CP}$, Braunwald E, McCabe $\mathrm{CH}$, Rader DJ, Rouleau $J \mathrm{~L}$, Belder R, et al. Intensive versus moderate lipid lowering with statins after acute coronary syndromes. N Engl J Med. 2004;350:1495-504. doi: 10.1056/NEJMoa040583.

11. Ye Y, Zhao X, Zhai G, Guo L, Tian Z, Zhang S. Effect of high-dose statin versus low-dose statin plus ezetimibe on endothelial function: a meta-analysis of randomized trials. J Cardiovasc Pharmacol Ther. 2012;17:357-65. doi: 10.1177/1074248412449384.

12. Tehrani S, Mobarrez F, Antovic A, Santesson P, Lins $P$, Adamson $U$, et al. Atorvastatin has antithrombotic effects in patients with type 1 diabetes and dyslipidemia. Thromb Res. 2010;126:e225-31. doi: 10.1016/j.thromres.2010.05.023

13. Stein EA, Lane M, Laskarzewski P. Comparison of statins in hypertriglyceridemia. Am J Cardiol. 1998;81:66B-69B.

14. Vernaglione L, Cristofano C, Muscogiuri P, Chimienti S. Does atorvastatin influence serum C-reactive protein levels in patients on long-term hemodialysis? Am J Kidney Dis. 2004;43:471-8. doi: 10.1053/j.ajkd.2003.11.008.

15. Lyngdoh T, Vollenweider P, Waeber G, Marques-Vidal P. Association of statins with inflammatory cytokines: a population-based Colaus study. Atherosclerosis. 2011;219:253-8. doi: 10.1016/j.atherosclerosis.2011.07.117

16. Gensini GF, Gori AM, Dilaghi B, Rostagno C, Gaw A, Blanco-Colio LM, et al. Effect of atorvastatin on circulating hsCRP concentrations: a sub-study of the achieve cholesterol targets fast with atorvastatin stratified titration (ACTFAST) study. Int J Cardiol. 2010;142:257-64. doi: 10.1016/j. ijcard.2008.12.213.

17. Arnaud C, Burger F, Steffens S, Veillard NR, Nguyen $\mathrm{TH}$, Trono D, et al. Statins reduce interleukin-6-induced C-reactive protein in human hepatocytes: new evidence for direct antiinflammatory effects of statins. Arterioscler Thromb Vasc Biol. 2005;25:1231-6. doi: 10.1161/01. ATV.0000163840.63685.0c 18.

18. Herder C, Klopp N, Baumert J, Müller M, Khuseyinova N, Meisinger $\mathrm{C}$, et al. Effect of macrophage migration inhibitory factor (MIF) gene variants and MIF serum concentrations on the risk of type 2 diabetes: results from the MONICA/KORA Augsburg Case-Cohort Study, 1984-2002. Diabetologia. 2008:51:276-84. doi:10.1007/s00125-007-0800-3.

19. Sell H, Dietze-Schroeder D, Eckel J. The adipocyte-myocyte axis in insulin resistance. Trends Endocrinol Metab. 2006;17:416-22. doi: 10.1016/j.tem.2006.10.010.

20. Donath MY, Schumann DM, Faulenbach M, Ellingsgaard H, Perren A, Ehses JA. Islet inflammation in type 2 diabetes: from metabolic stress to therapy. Diabetes Care. 2008;31 Suppl 2:S161-4. doi:10.2337/dc08-s243.

21. Antonopoulos AS, Margaritis M, Lee R, Channon K, Antoniades C. Statins as anti-inflammatory agents in atherogenesis: molecular mechanisms and lessons from the recent clinical trials. Curr Pharm Des. 2012;18:1519-30. doi:10.2174/138161212799504803.

22. Tousoulis D, Antoniades C, Vassiliadou C, Toutouza M, Pitsavos C, Tentolouris C, et al. Effects of combined administration of low dose atorvastatin and vitamin $E$ on inflammatory markers and endothelial function in patients with heart failure. Eur J Heart Fail. 2005;7:1126-32. doi: 10.1016/j.ejheart.2005.03.007.

23. Nawawi H, Osman NS, Yusoff K, Khalid BAK. Reduction in serum levels of adhesion molecules, interleukin-6 and C-reactive protein following short-term low-dose atorvastatin treatment in patients with non-familial hypercholesterolemia. Horm Metab Res. 2003;35:479-85. doi:10.1055/s-2003-41805. 
24. Ascer E, Bertolami MC, Venturinelli ML, Buccheri V, Souza J, Nicolau JC, et al. Atorvastatin reduces proinflammatory markers in hypercholesterolemic patients. Atherosclerosis. 2004;177:161-6. doi:10.1016/j.atherosclerosis.2004.07.003.

25. Liu Y, Hultén LM, Wiklund O. Macrophages isolated from human atherosclerotic plaques produce IL-8, and oxysterols may have a regulatory function for IL-8 production. Arterioscler Thromb Vasc Biol. 1997;17:317-23.

26. Tedgui A, Mallat Z. Anti-inflammatory mechanisms in the vascular wall. Circ Res. 2001;88:877-87.

27. Schroecksnadel K, Frick B, Winkler C, Wirleitner B, Weiss G, Fuchs D. Atorvastatin suppresses homocysteine formation in stimulated human peripheral blood mononuclear cells. Clin Chem Lab Med. 2005;43:1373-6. doi:10.1515/ CCLM.2005.234

28. Lüftjohann D, Sigit JI, Locatelli S, von Bergmann K, Schmidt $\mathrm{HH}$. High-dose simvastin $(80 \mathrm{mg} / \mathrm{d})$ decreases plasma concentrations of total homocyst(e)ine in patients with hypercholesteromia. Atherosclerosis. 2001;155:265-6. doi:10.1016/S0021-9150(00)00735-8.

29. Bolaman Z, Kadikoylu G, Ozgel N, Yenisey C. Effects of atorvastatin on coagulation parameters and homocysteine in patients with primary hypercholesterolemia. J Natl Med Assoc. 2006;98:1273-7.

30. Miltiadous G, Papakostas J, Chasiotis G, Seferiadis K, Elisaf M. Statins and homocysteine. Atherosclerosis. 2003;166:199_ 200. doi:10.1016/S0021-9150(02)00318-0.

31. Milionis HJ, Papakostas J, Kakafika A, Chasiotis G, Seferiadis K, Elisaf MS. Comparative effects of atorvastatin, simvastatin, and fenofibrate on serum homocysteine levels in patients with primary hyperlipidemia. J Clin Pharmacol. 2003;43:825-30. doi:10.1177/0091270003255920.

32. Giral P, Bruckert E, Jacob N, Chapman MJ, Foglietti MJ, Turpin G. Homocysteine and lipid lowering agents. A comparison between atorvastatin and fenofibrate in patients with mixed hyperlipidemia. Atherosclerosis. 2001;154:421-7.
doi:10.1016/S0021-9150(00)00474-3.

33. van der Loo B, Spring S, Koppensteiner R. High-dose atorvastatin treatment in patients with peripheral arterial disease: effects on platelet aggregation, blood rheology and plasma homocysteine. Clin Hemorheol Microcirc. 2011;47:241-51. doi:10.3233/CH-2011-1386.

34. Min L, Shao S, Wu X, Cong L, Liu P, Zhao H, et al. Antiinflammatory and anti-thrombogenic effects of atorvastatin in acute ischemic stroke. Neural Regen Res. 2013;8:2144-54. doi:10.3969/j.issn.1673-5374.2013.23.004.

35. Krysiak R, Gilowski W, Szkrobka W, Okopien B. The Effect of atorvastatin on cardiometabolic risk factors in bromocriptine-treated premenopausal women with isolated hypercholesterolemia. Cardiovasc Ther. 2015;33:282-7. doi:10.1111/1755-5922.12143.

36. Ridker PM, Rifai N, Pfeffer MA, Sacks F, Braunwald E. Long-term effects of pravastatin on plasma concentration of C-reactive protein. The Cholesterol and Recurrent Events (CARE) Investigators. Circulation. 1999;100:230-5.

37. Bełtowski J, Wójcicka G, Jamroz-Wiśniewska A. Adverse effects of statins - mechanisms and consequences. Curr Drug Saf. 2009;4:209-28. doi:10.2174/157488609789006949.

38. Nakata M, Nagasaka S, Kusaka I, Matsuoka H, Ishibashi S, Yada T. Effects of statins on the adipocyte maturation and expression of glucose transporter 4 (SLC2A4): implications in glycaemic control. Diabetologia. 2006;49:1881-92. doi:10.1007/s00125-006-0269-5

39. Hao M, Head WS, Gunawardana SC, Hasty AH, Piston DW. Direct effect of cholesterol on insulin secretion: a novel mechanism for pancreatic beta-cell dysfunction. Diabetes. 2007:56:2328-38. doi:10.2337/db07-0056.

40. Ballard KD, Parker BA, Capizzi JA, Grimaldi AS, Clarkson PM, Cole SM, et al. Increases in creatine kinase with atorvastatin treatment are not associated with decreases in muscular performance. Atherosclerosis. 2013;230:121-4. doi:10.1016/j.atherosclerosis.2013.07.001. 